\title{
Positive adjacency effects mediated by seed disperser birds in pine plantations
}

\author{
Regino Zamora, ${ }^{1}$ José Antonio Hódar, Luís Matías, and Irene Mendoza \\ Grupo de Ecología Terrestre, Departamento de Ecología, Facultad de Ciencias, Universidad de Granada, Av. Fuentenueva s/n, \\ E-18071, Granada, Spain
}

\begin{abstract}
This study examines the consequences of adjacent elements for a given patch, through their effects on zoochorous dispersion by frugivorous birds. The case study consists of pine plantations (the focal patch) adjacent to other patches of native vegetation (mixed patches of native forest and shrublands), and/or pine plantations. Our hypothesis is that input of native woody species propagules generated by frugivorous birds within plantations strongly depends on the nature of the surrounding vegetation. To test this hypothesis, we studied frugivorous-bird abundance, seed dispersion, and seedling establishment in nine pine plantation plots in contact with patches of native vegetation. To quantify adjacency arrangement effects, we used the percentage of common border between a patch and each of its adjacent elements. Frugivorous bird occurrence in pine plantations is influenced by the adjacent vegetation: the greater the contact with native vegetation patches, the more abundant were the frugivorous birds within pine plantations. Furthermore, frugivorous birds introduce into plantations the seeds of a large sample of native fleshy-fruited species. The results confirm the hypothesis that zoochorous seed rain is strongly determined by the kind of vegetation surrounding a given plantation. This finding underlines the importance of the composition of the mosaic surrounding plantations and the availability of mobile link species as key landscape features conditioning passive restoration processes.
\end{abstract}

Key words: adjacency; frugivorous birds; landscape mosaic; mobile links; passive restoration; pine plantations; seed dispersion.

\section{INTRODUCTION}

Pine plantations are widely distributed worldwide, and their naturalization is a current problem for ecologists, land managers, and landscape restorers (Wunderle 1997, Brockerhoff et al. 2008, Pejchar et al. 2008). The arrival of off-site propagules through organisms acting as mobile links is of special importance to plantations, where the internal resources for ecological succession are impoverished (Bengtsson et al. 2003, Lundberg and Moberg 2003, Gómez-Aparicio et al. 2009). However, monocultures of pine are unattractive to many seed-dispersing animals, such as frugivorous birds, because they lack the appropriate food resources. The distance of the plantation to native forests can modulate the probability of receiving a given off-site propagule (Parrota 1995, Keenan et al. 1997, Wunderle 1997, Ingle 2003).

Most terrestrial ecosystems are composed of adjacent patches with a different degree of human impact, forming a mosaic landscape (Wiens 1995, Hersperger 2006). It is a paradigm in the science of landscape ecology that different landscape units are linked by horizontal fluxes of biological information, and this flux

Manuscript received 14 January 2009; revised 30 June 2009; accepted 17 August 2009. Corresponding Editor: T. G. O’Brien.

${ }^{1}$ E-mail: rzamora@ugr.es depends on the degree of adjacency (Turner et al. 2001). In fact, the study of interactions between patches in a mosaic landscape has been a major focus of ecological research worldwide (Saunders et al. 1991, Forman 1995, Laurence and Bierregard 1997). During the last few years, researchers have developed certain concepts and methods to quantify this information flux between nearby landscape units. This is the case of "adjacency arrangement effects," described as the effect of adjacent elements on a patch (Hersperger and Forman 2003; see also Hersperger 2006). In this landscape context, patches in contact affect each other in a positive or negative way at the boundary, depending on (1) the quality of the focal patch as a source or sink of propagules in relation to the adjacent patches; (2) the spatial arrangement or juxtaposition of adjacent elements in an heterogeneous landscape; and (3) the kind of organisms considered and their movement ability, because many species perceive the landscape as a mosaic with a multiplicity of patch types, and their abundance varies accordingly (Wiens 1995, McIntyre and Hobbs 1999, Fischer et al. 2004).

The present study is directed at understanding the consequences of adjacent elements on a given patch, through its effects on the seed dispersal by frugivorous birds (see Plate 1). Our case study consists of pine plantation plots (the focal patch) adjacent to other patches of native vegetation (mixed patches of native 


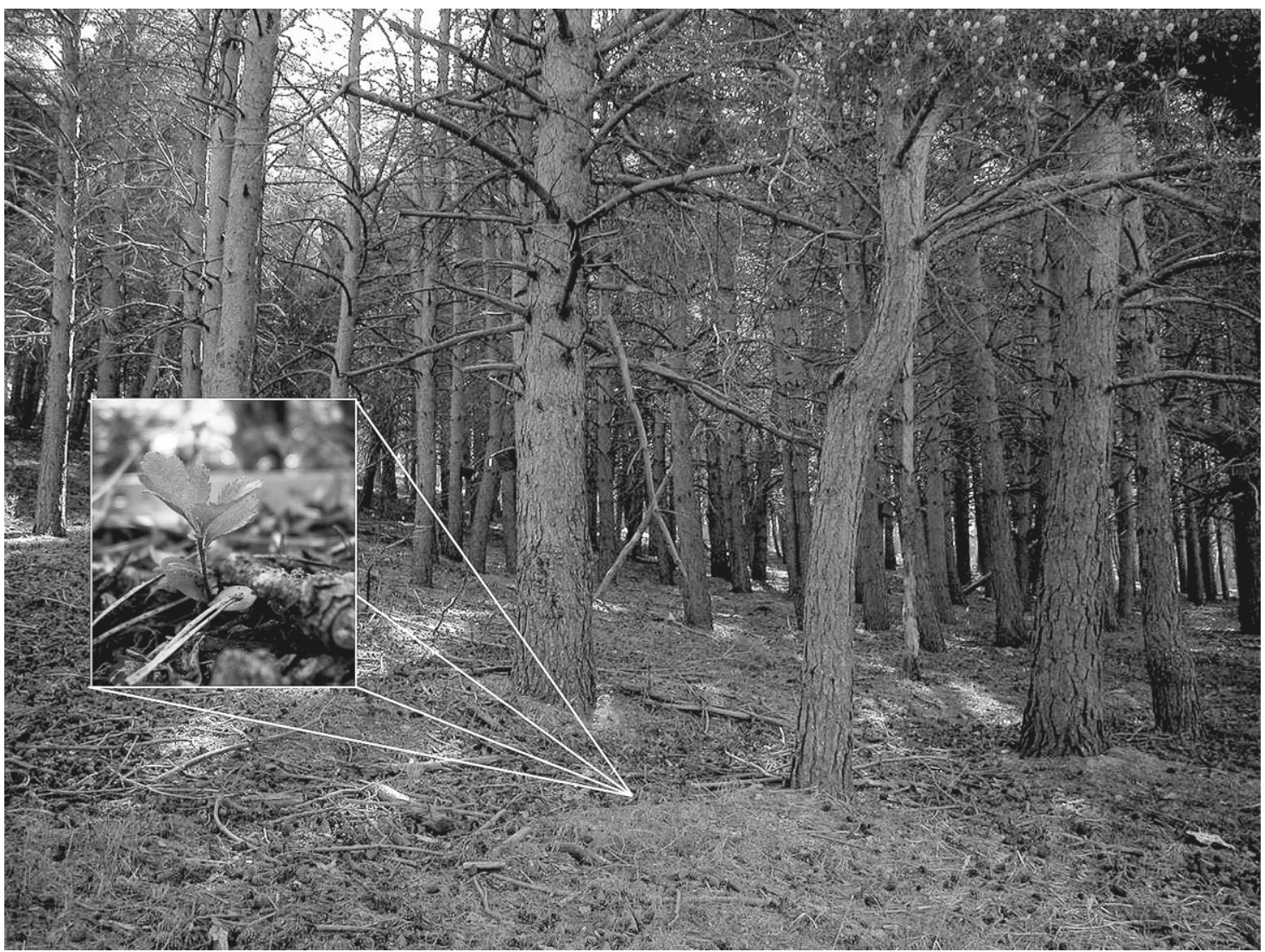

Plate 1. Plantations close to native vegetation are not biological deserts. Detail: A zoochorous seedling dispersed by frugivorous birds. Photo credits: L. Matías.

forest and shrublands) and/or pine plantations. Typically, forest plantations have low diversity and are thus spatially homogeneous habitats in comparison with native forests (Brockerhoff et al. 2008). The ecosystem transformation associated with intensive forestry drastically reduces the biological legacies within the planted area, including remnant native woody plants and their propagules. Consequently, the recuperation of community diversity within plantations strongly depends on "external ecological memory" (sensu Bengtsson et al. 2003) of nearby, well-conserved areas which can provide propagules for colonization from outside the plantation (Gómez-Aparicio et al. 2009).

The potential of plantations to facilitate recolonization processes has previously been indicated in a diverse sample of tropical (Lugo 1988, 1992, 1997, Parrota 1992, 1995, Brown and Lugo 1994, Tubelis et al. 2007) and temperate forests (Hewitt and Kellman 2002a, b). These studies indicate that recolonization depends on the degree of site degradation, proximity to native forest seed sources, and characteristics of the plantations, and suggest that most species of the sapling bank were dispersed by animals inhabiting native vegetation patches (Parrota 1995, Hewitt and Kellman 2002a,b).
However, to date, no studies are available explicitly analyzing the importance of the surrounding vegetation of "higher quality" (native vegetation) on key ecological processes within a given patch of "lower quality" (pine plantations), considering together different aspects of the recruitment, such as the diversity and abundance of the animal seed vectors, the diversity and abundance of the seed rain, and quantifying key demographic processes, such as seed and seedling limitation for an entire woody-plant community.

Our general hypothesis is that propagule input of native woody species by frugivorous birds within plantations strongly depends on the nature of surrounding vegetation, which represent the nearby "external memory" (sensu Bengtsson et al. 2003) that provides propagules from outside the plantation. To test this hypothesis, for three years we studied the frugivorous bird abundance, seed rain, and seedling recruitment in the same nine pine plantations plots (the target patch). These plots are in contact to different degrees with patches of native vegetation and/or pine plantations, forming a typical mountain mosaic landscape. Our study, though not experimental, did take into account the gradient of adjacency previously outlined for 
hypothesis testing, and we employed a design intended to separate (or at least minimize) the effects of factors other than the adjacency index on propagule input within plantation plots.

From our general hypothesis, we make the following more-specific two predictions: (1) Frugivorous-bird occurrence in the pine plantations patch will depend on the type of neighboring vegetation. To test this prediction, we use as a control the spatial distribution and abundance of non-frugivorous birds in the same nine plantation plots. (2) The spatial distribution and abundance of the bird-dispersed seeds must have a heterogeneous spatial distribution, with more zoochorous seeds in plantation plots closer to native vegetation. To test this prediction, we used as a control the spatial distribution and abundance of anemochorous seed rain in the same nine plantation plots. We also analyze the spatial distribution of zoochorous seedlings, using as a control the spatial distribution and abundance of anemochorous seedlings in the same nine plantation plots.

\section{Methods}

\section{Study area}

The study area is a mosaic composed of patches of different landscape units (pine plantations, fragments of native forests and shrublands) in contact with each other in Sierra Nevada National Park $\left(37^{\circ} 05^{\prime} \mathrm{N}, 3^{\circ} 28^{\prime} \mathrm{W}\right.$, Granada, southeast Spain). Fragments of native forest were dominated by Pinus sylvestris var. nevadensis Christ. mixed with another tree species such as Taxus baccata L., Acer opalus subsp. granatense Boiss and Quercus rotundifolia Desf. Native shrublands were composed of fleshy-fruited shrub species, principally Berberis vulgaris subsp. australis Boiss., Crataegus monogyna Jacq., Rosa sp., Rubus sp., Lonicera sp., and Prunus ramburii Boiss.

The Sierra Nevada mountain area has a continental Mediterranean climate, with cold winters and hot, dry summers. The study ran from 2003 to 2005 . These years showed contrasting rainfall patterns: 2003 and 2004 were considered normal years in terms of annual rainfall (750 mm/yr); by contrast, 2005 (394 mm/yr) was the driest year of a 46-year series.

The frugivorous guild is composed of birds of small (Robin and Blackcap, 12-20 g) and medium (thrushes, 60-120 g) size birds. Most of these species are sedentary in the study area (Zamora and Camacho 1984, 1985), except Redwing and Ring-ouzel, which are long-distance migrant birds. All of these species are omnivorous, have a frugivore-based diet during autumn-early winter, and are legitimate seed dispersers of many plants bearing fruits in Mediterranean mountains (Herrera 1984, Zamora 1990, Jordano 1993).

\section{Spatial framework}

As a focal case study, nine pine plantation plots were selected, all being mixed plantations of $P$. sylvestris and
P. nigra of nearly $15 \mathrm{~m}$ in height and of the same age (55 years). All plots were in the same mountain sector of $2 \times$ $2 \mathrm{~km}$ of Sierra Nevada, in the same altitudinal range (1700-1840 m) and slope (southwest). Study plots had an average size of $0.4 \pm 0.28$ ha (mean \pm SD) per plot, with quadrat-oval shape, and an average distance between the plots of $778.4 \pm 461.7 \mathrm{~m}$. Plot sizes and perimeters were determined with a centimeter-precision GPS (Leica SR 500; Leica Geosystems, Heerbrugg, Switzerland). To determine the adjacency with nearby vegetation with respect to a given plantation plot, we followed the perimeter of each plantation plot using GPS to measure the linear meters of contact with another pine plantation, or with native vegetation, using the method proposed by Hersperger and Forman (2003). The values of the adjacency-arrangement index varied from $100 \%$ (in this case, the focal plot was completely surrounded by native forest-shrubland patches), to $0 \%$ values, (in this case, the focal plot was completely surrounded by other pine plantations).

Because we were interested specifically in analyzing adjacency effects in a gradient context, the selected target plots consistently had a percentage value of perimeter in contact with other patches of native forestshrubland patches (from $0 \%$ to 99.8\%) and/or a percentage value of perimeter in contact with other plantations of similar composition, age and height (see Table 1). The sectors of the perimeter in contact with native vegetation had strong contrast between the homogeneous structure of the plantation plot and the heterogeneous structure of the nearby forest-shrubland patches, whereas the sector of the perimeter in contact with plantations had no evident edge.

To sample the adult canopy in each plantation plot, we counted all the pine individuals present in each plot. The plantations contained saplings and vegetative individuals of fleshy fruiting woody plants (Mendoza et al. 2009) but no reproductive plants with mature fruits as potential seed sources. Thus, seeds from fleshy-fruited plants found within plantations must have come from the trees and shrubs bearing fruits outside the plantation, in the nearby patches of native vegetation, where all woody, fleshy-fruit-bearing species produced fruits during the three study years (Mendoza et al. 2009). In these nine target plots, we conducted (1) bird censuses, (2) seed-rain sampling, and (3) seedlings counts. Sampling was carried out for three consecutive years for bird censuses and seed rain, and two years for seedling recruitment.

\section{Bird-censusing methodology}

Censuses were performed consistently between one and four hours after sunrise. No census was carried out with strong wind or rain. The censusing method was by point counts, with 12 minutes in total for each census per plot (Verner 1985). A sampling location was established at the middle of the focal plot. All birds registered within the boundary of the focal pine plot, 
TABLE 1. Summary of the variables considered in the analysis.

\begin{tabular}{|c|c|c|c|c|c|c|c|c|}
\hline \multirow[b]{2}{*}{ Plot } & \multirow[b]{2}{*}{$\begin{array}{l}\text { Stand density } \\
\text { (trees/ha) }\end{array}$} & \multirow[b]{2}{*}{$\begin{array}{l}\text { Adjacency } \\
\text { index }(\%)\end{array}$} & \multicolumn{2}{|c|}{$\begin{array}{c}\text { Bird density } \\
\left(\text { birds } \cdot \mathrm{ha}^{-1} \cdot[3 \mathrm{yr}]^{-1}\right)\end{array}$} & \multicolumn{2}{|c|}{$\begin{array}{c}\text { Seed limitation } \\
\left(\text { seeds } \cdot \text { plot }^{-1} \cdot[3 \mathrm{yr}]^{-1} \text { ) }\right.\end{array}$} & \multicolumn{2}{|c|}{ 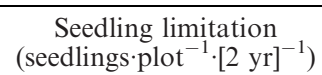 } \\
\hline & & & Frugivorous & $\begin{array}{c}\text { Non- } \\
\text { frugivorous }\end{array}$ & Zoochorous & $\begin{array}{l}\text { Anemo- } \\
\text { chorous }\end{array}$ & Zoochorous & $\begin{array}{l}\text { Anemo- } \\
\text { chorous }\end{array}$ \\
\hline 1 & 677.5 & 9.71 & 0.54 & 4.49 & 0.80 & 0.00 & 1.00 & 1.00 \\
\hline 2 & 455.6 & 7.39 & 0.14 & 4.80 & 0.53 & 0.00 & 0.86 & 1.00 \\
\hline 3 & 432.1 & 39.05 & 1.94 & 10.73 & 0.47 & 0.00 & 0.75 & 0.93 \\
\hline 4 & 857.5 & 20.68 & 0.18 & 6.03 & 0.67 & 0.00 & 1.00 & 1.00 \\
\hline 5 & 1132.0 & 33.16 & 0.98 & 10.20 & 0.67 & 0.00 & 1.00 & 1.00 \\
\hline 6 & 1136.6 & 0 & 0.18 & 11.48 & 0.80 & 0.00 & 1.00 & 1.00 \\
\hline 7 & 1085.6 & 99.87 & 7.75 & 9.97 & 0.40 & 0.07 & 0.89 & 1.00 \\
\hline 8 & 634.6 & 44.18 & 6.96 & 19.22 & 0.40 & 0.00 & 0.89 & 1.00 \\
\hline 9 & 1496.9 & 24.24 & 1.50 & 20.12 & 0.80 & 0.00 & 0.67 & 1.00 \\
\hline
\end{tabular}

Note: See Methods for details of index calculations.

either sightings or hearings, were counted. The number of censuses per plot varied from four to seven per year during the period where fruits were available in our study area (September-December, 2003-2005). All censuses were performed by two trained observers (J. A. Hódar and R. Zamora). Density was calculated as the number of birds divided by the area of each plot, and is expressed as birds/ha. Our main focus was the composition and abundance of the frugivorous-bird guild. Moreover, we also used the abundance of the rest of non-frugivorous species as a control of the distribution of frugivorous birds.

\section{Seed rain}

Using seed traps, we quantified seed rain from October 2002 to May 2005 (three complete dispersal seasons). A pair of seed traps $21 \mathrm{~cm}$ in diameter was located at each sampling station $(n=15$ sampling stations per plot, for a total of 135 seeds sampling stations). Seed traps were located $15-30 \mathrm{~m}$ from the plantation border and were evenly distributed around the center of the plot. We used pots nailed to pine trees at $160 \mathrm{~cm}$ in height. Traps were protected against postdispersal seed predation by a wire mesh. All the seeds were identified to the species level, grouping the collected seeds into bird-dispersed seeds, and winddispersed seeds, which we used as a control for statistical comparisons between the two functional groups of seeds. The genus Quercus was excluded from all analyses because our seed traps were not suitable for sampling its seed rain (wire mesh was not wide enough to allow acorn pass, and jay, the main disperser of the species, buries acorns in the ground).

To determine whether the lack of seeds was a limiting factor for recruitment within the pine plantations, we used the seed-limitation index, calculated as the proportion of sampling stations per plot not receiving seeds (Muller-Landau et al. 2002). The values of this index varied from 0 (no seed limitation) to 1 (total seed limitation). We calculated this index both for zoochorous and anemochorous seeds.

\section{Seedling bank}

The composition and abundance of the seedling bank was monitored using two $1-\mathrm{m}^{2}$ quadrats per sampling located close to each pair of seed traps in the same sampling station as the seed-trap station $(n=15$ sampling stations per plot). Survival of the one-year (2005 cohort) and two-year (2004 cohort) emerged seedlings was monitored at the end of the summer of 2005. We grouped the seedlings into "zoochorous" and "anemochorous." We calculated an index of establishment limitation as the proportion of sampling stations receiving seeds where seedlings did not become established (Muller-Landau et al. 2002).

\section{Statistical analysis}

Concordance between the adjacency index and the response variables was evaluated on a per plot basis by means of correlation and regression models. Predictor variables were (1) the adjacency index (percentage of the perimeter of the plantation plot in contact with native forest, and/or with more pine plantations) and (2) pine density within plots. There was no correlation between the two predictor variables $\left(r^{2}=0.014, P=0.758, n=9\right)$. Dependent variables were (1) the abundance of frugivorous and non-frugivorous birds per plot and year; (2) the total input of zoochorous and anemochorous seeds per plot; (3) the seed-limitation index, calculated both for zoochorous and anemochorous seeds per plot; and (4) the seedling-limitation index, also calculated for both zoochorous and anemochorous seedlings. We use untransformed data for analysis because the variables did not show significant departures from normality (tree density, $W=0.938, P=0.758$; adjacency, $W=0.850, P=$ 0.074; Shapiro-Wilks test).

\section{RESULTS}

\section{Frugivorous bird}

Six species of frugivorous birds were identified during the censuses, namely European Robin (Erithacus rubecula), Blackcap (Sylvia atricapilla), Redwing Blackbird (Turdus iliacus), Common Blackbird (Turdus merula), Mistle Thrush ( $T$. viscivorus), and Ring Ouzel ( $T$. 
torquatus), all of them appearing in all three study years. Blackbird, Ring Ouzel, and Robin were the most common birds in all the plots.

During the three study years, differences in frugivorous bird abundance within study plots (Table 1) did not show any relationship with tree density $(P>0.3, N=9$ plots in the regression). However, the perimeter of the plantation in contact with native vegetation had a positive effect on the abundance of frugivorous birds: higher contact with native forests was associated with higher abundances of frugivorous birds within reforestation stands $\left(2003, r^{2}=0.597, P=0.06 ; 2004, r^{2}=\right.$ $0.917, P<0.001 ; 2005, r^{2}=0.655, P=0.041$; see Fig. 1$)$. On the contrary, non-frugivore passerine birds (mostly Parus spp.) showed no statistically significant association with the percentage of the perimeter of the plantation in contact with native vegetation $\left(2003, r^{2}=\right.$ $0.144, P=0.628 ; 2004, r^{2}=0.227, P=0.462 ; 2005, r^{2}=$ $0.500, P=0.2$, Fig. 1$)$, or with pine density $(P>0.2$ for the three years).

\section{Seed rain}

A total of 115 zoochorous seeds from 11 woody species (34 Rubus ulmifolius; 28 Crataegus monogyna; 13 Berberis vulgaris and Rosa spp.; 7 Prunus ramburii and Amelanchier ovalis; 6 Juniperus communis; 4 Lonicera xylosteum; 1 Sorbus aria, Juniperus sabina, and Arctostaphyllos uva-ursi) were collected in the seed traps during the three study years. This represents a seed rain average of 3.7 seeds $\cdot \mathrm{plot}^{-1} \cdot \mathrm{yr}^{-1}$ (see Table 1). There was a positive relationship between frugivorous bird abundance and zoochorous seed rain during the three study years on a per-plot basis, significant in 2003 and $2005\left(r^{2}\right.$ $=0.499$, and $r^{2}=0.459, P<0.05$, respectively).

Because all nine plots had a similar small size and shape, and seed traps were placed at a similar distance from the border in all plots (see Methods), the major potential sources of variations in seed rain were variations in the surrounding vegetation to the plot. We investigated the potential relationships between adjacency in reforestations vs. zoochorous seed limitation, finding a positive relationship (Fig. 2). When the percentage of the perimeter of pine plantations in contact with native vegetation was higher, seed limitation was lower, with values ranging from 0.4 (moderate limitation) in plots with higher proportion in contact with native forests to 0.8 (almost total seed limitation) when a given plot was surrounded by other pine plantations $\left(r^{2}=0.487, P<0.037\right)$. On the other hand, there was no seed limitation for anemochorous seeds within plantations, with most plots receiving seeds at any point (Fig. 2).

\section{Seedling bank}

In our sapling quadrats, we counted a total of 88 emerged seedlings during the spring of 2004, and only six during the 2005 spring, belonging to 11 fleshy-fruited species (C. monogyna, R. ulmifolius, Rosa spp., Lonicera

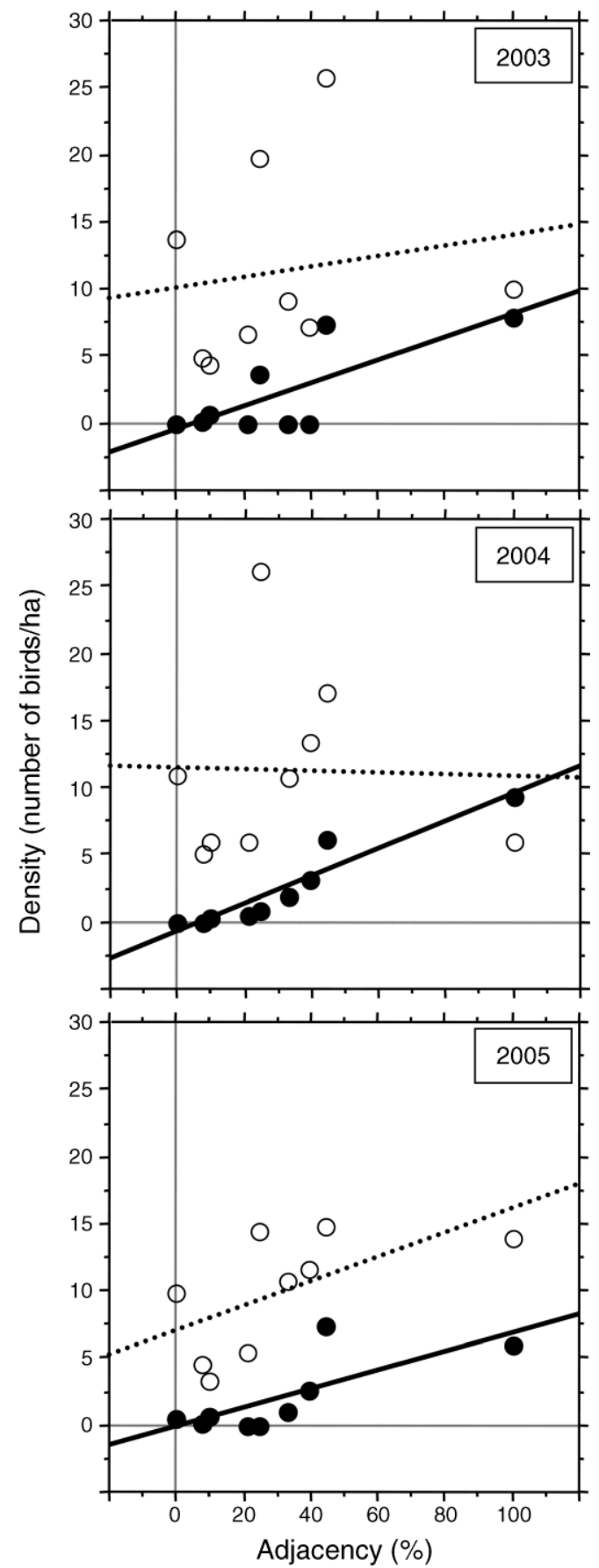

FIG. 1. Relationships between the adjacency index (percentage value of perimeter in contact with other patches) as predictor variable and the density of frugivorous birds (solid circles) and non-frugivores birds (open circles) as response variable during the three study years.

spp., B. vulgaris, Amelanchier ovalis, Sorbus aria, P. ramburii, Hedera helix, Cotoneaster granatensis, and Juniperus sp.). Nine of these 11 species found in the seedling bank were the same species that those found in the seed rain pool $\left(\chi^{2}=0.430, P=0.999\right.$, chi-square test $)$, with the most abundant species in the seed rain also 


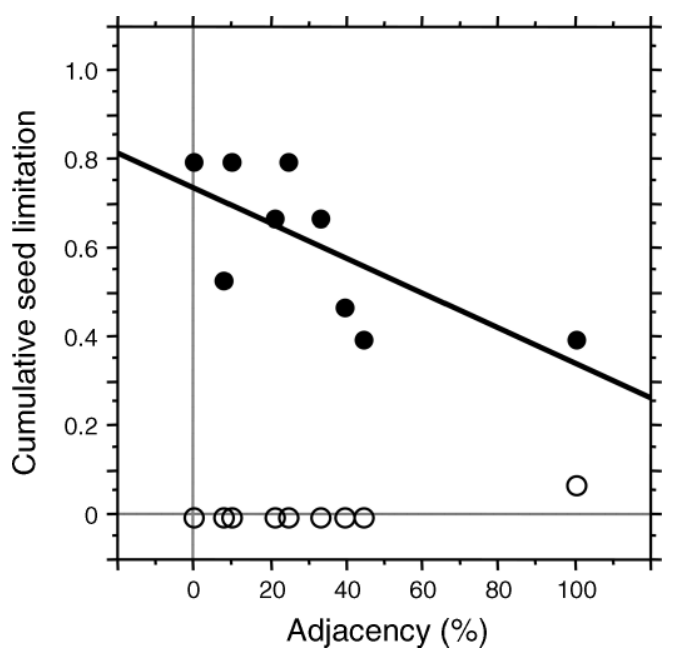

FIG. 2. Relationships between the adjacency index as predictor variable and seed limitation as response variable (seed rain data for 2003, 2004, and 2005 combined) for zoochorous seeds (solid circles, solid line); $R^{2}=0.487, P<$ 0.037 ) and anemochorous seeds (open circles).

being the most abundant in the seedling bank (Rubus ulmifolius, Crataegus monogyna, and Rosa sp.).

Only 19 seedlings (16 zoochorous, 3 anemochorous) survived after the summer of 2005 due to an extreme drought. Consequently, fleshy-fruited woody species showed very high values of establishment limitation at the end of the study, whereas anemochorous species showed total limitation. The consequence of this episode of recruitment failure is a spatially homogeneous mortality, with most plots having no surviving seedling in any point. As a result, no statistical relationship emerges when comparing adjacency index with zoochorous and anemochorous seedlings (zoochorous, $r^{2}=$ 0.037, $P=0.62$; anemochorous, $\left.r^{2}=0.010, P=0.794\right)$.

\section{DisCUSSION}

In our study system, frugivorous-bird occurrence and zoochorous seed dispersion in pine plantations were strongly determined by the kind of vegetation surrounding a given plantation. Nearby patches of native vegetation provided two fundamental services to plantations: (1) a diverse and abundant array of propagules available for potential colonization, and (2) a diverse and abundant guild of frugivorous birds, which behaved as short to medium mobile link organisms (sensu Lundberg and Moberg 2003), by carrying seeds from native forest and shrubland patches (the "support area") to the low-diversity, homogeneous pine plantations (the "disturbed site"). This finding underlines the importance of the composition of the mosaic surrounding the focal patch.

\section{Adjacency and frugivorous birds}

According to our first prediction, the greater the contact with native vegetation patches, the more abundant were the frugivorous birds within pine plantations, and this pattern was consistent, at least over the three study years (Fig. 1). Observations of birdforaging behavior during censuses indicated that frugivorous birds enter the pine plantation to perch or rest after foraging bouts in the surrounding native vegetation. There are hardly any adults, reproductive plants bearing fruits within plantations, probably because the scarce light (Mendoza et al. 2009). We are confident that most of seeds that fell into the seed traps came from the woody species bearing fleshy fruits adjacent to pine plots, since small birds (e.g., Robin) rarely disperse seeds more than $100 \mathrm{~m}$ from the seed source, whereas medium-sized birds (Turdus spp.) moved seeds both short to medium distances (Jordano et al. 2007).

Thanks to native vegetation, frugivorous birds extended their home ranges to nearby plantations (see also Tubelis et al. 2004, 2007). In structural terms, our landscape mosaic was composed of pine plantations and forest-shrubland patches in contact with each other. In functional terms, a plantation closer to a native forest is much more suitable for frugivorous birds than are plantation plots surrounded by more plantations.

\section{Adjacency, seed rain, and recruitment potential}

In accordance with our second prediction, the results clearly indicate a consistent spatial pattern of seed rain: the greater the percentage of the perimeter of pine plantations in contact with native vegetation, the higher the frugivorous bird abundance and, consequently, plantations closer to native vegetation received more zoochorous seeds (Fig. 2). Frugivorous birds dispersed seeds from nearly half the total native fleshy-fruited woody species available in the study area (Mendoza et al. 2009). Furthermore, the pool of species found in the seed rain was very similar to the zoochorous seedlings and saplings bank found in plantations, which were also very similar to the seedling and sapling bank in nearby patches of native forests in the same mountain ranges (Quero et al. 2008, Mendoza et al. 2009). A large number of Mediterranean fleshy-fruited woody species are late-successional shade-tolerant species (Herrera 1995). Therefore, fleshy-fruited species dispersed by frugivorous birds will have a comparatively higher probability of persisting in the dark understorey of plantations, benefiting from the mild microclimate generated by the canopy (Gómez-Aparicio et al. 2009, Mendoza et al. 2009; see also Lugo [1988, 1992], Parrota [1992, 1995], Brown and Lugo [1994], Keenan et al. [1997], and Tubelis et al. [2004] for tropical forests, and Hewitt and Kellman [2002a, $b]$ for temperate forests).

When the seed rain data in pine plantations provided in this study for birds were compared with the corresponding data provided by mammals in pine plantation plots of the same study area (Matías et al. 2010) the following major similarities and differences appeared: (1) Both birds and mammals dispersed seeds from a very similar sample of native species, mostly 
Rubus, Crataegus, and Rosa (although in different proportions for some species). (2) Whereas mammals are considered long-distance dispersers (Jordano et al. 2007, Matías et al. 2010), our dominant bird species proved to be mainly short- to medium-distance dispersers. For this reason, birds did not disperse agricultural species from distant farmlands into plantations as mammals do (Matías et al. 2010). (3) Propagule input by birds was quantitatively more important than mammal dispersal $(94.5 \%$ against 5\%, representing 3.7 seeds $\cdot \mathrm{m}^{-2} \cdot \mathrm{yr}^{-1}$ dispersed by birds vs. 0.2 seeds $\cdot \mathrm{m}^{-2} \cdot \mathrm{yr}^{-1}$ dispersed by mammals). For all of these reasons, frugivorous birds are the key mobile links (Lundberg and Moberg 2003) connecting the external nearest sources for colonization (patches of native vegetation) with the pine plantations.

\section{Concluding remarks}

Overall, the results found in this study support our main hypothesis that zoochorous dispersion by birds is strongly determined by the adjacent vegetation to the plantation plot. Such positive adjacency effects constitutes robust evidence of strong interactions (sensu Hersperger 2006) between nearby landscape elements mediated by frugivorous birds, key mobile links organisms, with potential consequences for plant community dynamics. In a landscape mosaic, low-quality patches can benefit from contact with higher-quality patches, allowing passive restoration mechanisms thanks to animals acting as propagule vectors for recolonization (Lundberg and Moberg 2003). Furthermore, our results strongly support that the strength of the interaction also depends on the degree of juxtaposition of adjacent elements in a heterogeneous landscape (Hersperger 2006). The positive adjacency effects demonstrated in this paper revive the old meaning of the edge effects, as formulated by Leopold (1933), a fundamental concept in classical ecology which emphasized the positive value of the contact between contiguous landscape units fostering diversity at different spatial scales (Harris 1984). Clearly, adjacency effects are an important factor for understanding the ecology of landscapes and, consequently, should be explicitly addressed in future studies (Hersperger and Forman 2003, Hersperger 2006). This opens the door for an effective integration of ecosystem and landscape ecology mediated by key processes driven by mobile link species (Lundberg et al. 2008).

\section{Restoration implications}

From an applied standpoint, the results found in this study demonstrate for the first time that frugivorous birds are the drivers of a passive restoration processes, introducing into plantations the seeds of a large sample of native fleshy-fruited species available in a given landscape. With encouragement of these adjacency effects, zoochorous propagule input can become qualitatively and quantitatively important. Clearly, seed availability is a main limiting factor in the restoration of woody plant biodiversity, making seed dispersal a key topic in the theoretical grounds of restoration ecology (Howe and Miriti 2004, Méndez et al. 2008).

Management strategies in our landscape framework should take into account that the fate of plantations depends heavily on (1) distance to native vegetation and (2) the availability of mobile link species. Accordingly, the management of biodiversity of plantations at the landscape level should consider both the spatial arrangement of plantation stands with respect to nearby native vegetation patches as a source of propagules as well as the abundance and spatial distribution of zoochorous seed vectors.

\section{ACKNOWLEDGMENTS}

We thank Consejería de Medio Ambiente, Junta de Andalucía, and the Director of Sierra Nevada National Park for field work permission. We are very grateful to Francisco Javier Bonet (Curro) for plot size delimitation. Daniel García, Luis Cayuela, and Lorena Gómez-Aparicio gave us valuable comments on earlier drafts of this paper. David Nesbitt carefully reviewed the English. Comments of three anonymous reviewers have improved this work. Financial support was provided by project MMA 24/2003 and GESBOME project RNM 1890) from the Excellence Research Programme of the Andalusian Government.

\section{Literature Cited}

Bengtsson, J., P. Angelstam, T. Elmqvist, U. Emanuelsson, C. Folke, M. Ihse, F. Moberg, and M. Nystrom. 2003. Reserves, resilience and dynamic landscapes. Ambio 32:389-396.

Brockerhoff, E. G., H. Jactel, J. A. Parrotta, C. P. Quine, and J. Sayer. 2008. Plantation forests and biodiversity: oxymoron or opportunity? Biodiversity and Conservation 17:925-951.

Brown, S., and A. E. Lugo. 1994. Rehabilitation of tropical lands: a key to sustaining development. Restoration Ecology 2:97-111.

Fischer, J., D. B. Lindemayer, and I. Fazey. 2004. Appreciating ecological complexity: habitat contours as a conceptual landscape model. Conservation Biology 18:1245-1253.

Forman, R. T. T. 1995. Land mosaics: the ecology of landscapes and regions. Cambridge University Press, Cambridge, UK.

Gómez-Aparicio, L., M. A. Zavala, F. Bonet, and R. Zamora. 2009. Are pine plantations valid tools for restoring Mediterranean forests? An assessment along abiotic and biotic gradients. Ecological Applications 19:2124-2141.

Harris, L. D. 1984. The fragmented forest: island biogeogrpahy theory and the preservation of biotic diversity. The University of Chicago Press, Chicago, Illinois, USA.

Hersperger, A. M. 2006. Spatial adjacencies and interactions: neighborhood mosaics for landscape ecological planning. Landscape and Urban Planning 77:227-239.

Hersperger, A. M., and R. T. T Forman. 2003. Adjacency arrangement effects on plant diversity and composition in woodland patches. Oikos 101:279-290.

Herrera, C. M. 1984. A study of avian frugivores, birddispersed plants, and their interaction in Mediterranean scrublands. Ecological Monographs 54:1-23.

Herrera, C. M. 1995. Plant-vertebrate seed dispersal systems in the Mediterranean: ecological, evolutionary and historical determinants. Annual Review of Ecology and Systematics 26: 705-727.

Hewitt, N., and M. Kellman. 2002a. Tree seed dispersal among forest fragments: I. Conifer plantations as seed traps. Journal of Biogeography 29:337-349. 
Hewitt, N., and M. Kellman. 2002b. Tree seed dispersal among forest fragments: II. Dispersal abilities and biogeographical controls. Journal of Biogeography 29:351-363.

Howe, H. F., and M. N. Miriti. 2004. When seed dispersal matters. BioScience 54:651-660.

Ingle, N. R. 2003. Seed dispersal by winds, birds, and bats between Philippine montane rainforest and successional vegetation. Oecologia 134:251-261.

Jordano, P. 1993. Geographical ecology and variation of plantseed disperser interactions: southern Spanish junipers and frugivorous thrushes. Vegetatio 107/108:85-104.

Jordano, P., C. García, J. A. Godoy, and J. L. García-Castaño. 2007. Differential contribution of frugivores to complex seed dispersal patterns. Proceedings of the National Academy of Sciences USA 104:3278-3282.

Keenan, R., D. Lamb, O. Woldring, T. Irvine, and R. Jensen. 1997. Restoration of plant biodiversity beneath tropical tree plantations in Northern Australia. Forest Ecology and Management 99:117-131.

Laurence, W. F., and R. O. Bierregaard. 1997. Tropical forest remnants. Ecology, management and conservation of fragmented communities. University of Chicago Press, Chicago, Illinois, USA.

Leopold, A. 1933. Game management. Charles Scribner and Sons, New York, New York, USA.

Lugo, A. E. 1988. The future of the forest: ecosystem rehabilitation in the tropics. Environment 30:16-20.

Lugo, A. E. 1992. Tree plantations for rehabilitating damaged forest lands in the tropics. Pages 2247-2255 in M. K. Wali, editor. Ecosystem rehabilitation. Volume 2: Ecosystem analysis and synthesis. Academia Publishing, The Hague, The Netherlands.

Lugo, A. E. 1997. The apparent paradox of reestablishing species richness on degraded lands with tree monocultures. Forest Ecology and Management 99:9-19.

Lundberg, J., E. Andersson, G. Cleary, and T. Elmquist. 2008. Linkages beyond borders: targeting spatial processes in fragmented urban landscapes. Landscape Ecology 23:717726.

Lundberg, J., and F. Moberg. 2003. Mobile links organisms and ecosystem functioning: implications for ecosystem resilience and management. Ecosystem 6:87-98.

Matías, L., R. Zamora, I. Mendoza, and J. A. Hódar. 2010. Seed dispersal patterns by large frugivorous mammals in a degraded mosaic landscape. Restoration Ecology [doi: 10. $1111 / \mathrm{j} .1526-100 \mathrm{X}]$

McIntyre, S., and R. R. Hobbs. 1999. A framework for conceptualizing human effects on landscapes and its relevance to management and research models. Conservation Biology 13:1282-1292.

Méndez, M., D. García, F. T. Maestre, and A. Escudero. 2008. More ecology is needed to restore Mediterranean ecosystems: a reply to Valladares and Gianoli. Restoration Ecology 16: 210-216.

Mendoza, I., L Gómez-Aparicio, R. Zamora, and L. Matias. 2009. Seed limitation vs. establishment limitation of the woody plant community in a degraded Mediterranean landscape: implications for conservation. Journal of Vegetation Science 20:367-376.

Muller-Landau, H. C., S. J. Wright, O. Calderón, S. P. Hubbell, and R. B. Foster. 2002. Assessing recruitment limitation: concepts, methods and case-studies from a tropical forest. Pages 35-54 in D. J. Levey, W. R. Silva, and M. Galetti, editors. Seed dispersal and frugivory: ecology, evolution and conservation. CAB International, Wallingford, Oxfordshire, UK.

Parrota, J. A. 1992. The role of plantation forests in rehabilitating degraded tropical ecosystems. Agriculture Ecosystem Environment 41:115-133.

Parrota, J. A. 1995. Influence of overstory composition on understory colonization by native species in plantations on a degraded tropical site. Journal of Vegetation Science 6:627636.

Pejchar, L., R. M. Pringle, J. Ranganathan, J. R. Zook, G. Duran, F. Oviedo, and G. C. Daily. 2008. Birds as agents of seed dispersal in a human-dominated landscape in southern Costa Rica. Biological Conservation 141:536-544.

Quero, J. L., L. Gómez-Aparicio, R. Zamora, and F. T. Maestre. 2008. Shifts in the regeneration niche of an endangered tree (Acer opalus ssp. granatense) during ontogeny. Basic and Applied Ecology 9:635-644.

Saunders, D. A., R. J. Hobbs, and C. R. Margules. 1991. Biological consequences of ecosystem fragmentation: a review. Conservation Biology 5:18-32.

Tubelis, D. P., D. B. Lindermayer, and A. Cowling. 2004. Novel match-matrix interactions: match width influences matriz use by birds. Oikos 107:634-644.

Tubelis, D. P., D. B Lindermayer, and A. Cowling. 2007. Bird population in native forest patches in south-eastern Australia: the roles of match width, matriz type (age) and matrix use. Landscape Ecology 22:1045-1058.

Turner, M., R. H. Gardner, and R. V. O'Neill. 2001. Landscape ecology in theory and practice. Pattern and processes. Springer, New York, New York, USA.

Verner, J. 1985. Assessment on counting techniques. Pages 247302 in R. F. Johnson, editor. Current ornithology. Volume 2. Plenum Press, New York, New York, USA.

Wiens, J. 1995. Landscape mosaics and ecological theory. Pages 1-26 in L. Hansson, L. Fahrig, and G. Merriam, editors. Mosaic landscapes and ecological processes. Chapman and Hall, London, UK.

Wunderle, J. M. 1997. The role of animal seed dispersal in accelerating native forest regeneration on degraded tropical lands. Forest Ecology and Management 99:223-235.

Zamora, R. 1990. The fruit diet of Ring-Ouzels (Turdus torquatus) wintering in Sierra Nevada (south-east Spain). Alauda 58:67-70.

Zamora, R., and I. Camacho. 1984. Evolución estacional de la comunidad de aves en un encinar de Sierra Nevada. Doñana, Acta Vertebrata 11:25-43.

Zamora, R., and I. Camacho. 1985. Evolución estacional de la comunidad de aves en un robledal de Sierra Nevada. Doñana, Acta Vertebrata 11:129-150. 